\title{
Numerical simulation of pile geothermal heat exchanger with spiral tube considering its thermo-mechanical behavior
}

\section{Deqi WANG}

Lin LU*
Ping CUI

\begin{abstract}
Pile geothermal heat exchanger (PGHE), which utilizes the building foundation piles as part of the geothermal heat exchangers (GHEs) for a groundcoupled heat pump (GCHP) system, has been attracting the interests of researchers and engineers. However, the continuous heat rejection/ extraction of the PGHE to/from the piles will cause significant temperature variations (up to $25^{\circ} \mathrm{C}$ ) of piles and the surrounding soil, which can influence the mechanical behavior of the pile foundation severely. A modified direct shear apparatus has been developed to investigate the interface behavior between soil and pile. Then, based on the experiment results, the thermo-mechanical behavior of PGHE with spiral coils was investigated by a 3-D simulation model. The thermal loads induce additional compressive stress when the temperature rise, and the local compressive stress can reach to 9.35MPa near the beat exchanger pipe. Additionally, heat extraction led to a decrease of friction angle and normal contact pressure at the interface between soil and pile, and as a consequence, the shear force decreases with the temperature drop. Compared with no thermal disturbance, the ultimate friction resistance of pile is weakened by $15.37 \%$.
\end{abstract}

\section{INTRODUCTION}

Ground-coupled heat pump (GCHP) technology, utilizing the shallow geothermal energy and heat capacity, has become an attractive alternative for space heating and cooling. Traditionally, the ground heat exchanger (GHE) consists of connected high-density polyethylene (HDPE) U-tubes buried in a number of ground boreholes with depth ranging from 50 to $120 \mathrm{~m}$ and separated space in 4 to $5 \mathrm{~m}$ (Wang et al., 2016). The heat exchange fluid is circulated inside the HDPE pipes. In general, the GHE with vertical boreholes requires a higher initial cost and a large plot of land for borehole installation, which has consequently hindered the wide applications of the technology in denselypopulated cities. Luckily, a novel pile GHE (PGHE), which utilizes the building foundation piles as part of the GHE for a GCHP system, has been attracting the interests of researchers and engineers.

However, the continuous heat rejection/extraction of the PGHE to/from the piles will cause significant temperature variations (up to $20^{\circ} \mathrm{C}$ ) of piles and the surrounding soil, which can influence the mechanical behavior of the pile foundation (Laloui et al., 2006). With temperature rise/drop and different thermal expansion coefficients of pile and soil, the thermal deformation between piles and the surrounding soil will become inconsistent and the stress

*vivien.lu@polyu.edu.hk, The Hong Kong Polytechnic University 
on the pile-soil interface would change (Knellwolf et al., 2011). The pile expands with the increase of its temperature, and accordingly the axial fixity at the head and toe of the pile and the lateral constraint from the surrounding soil would cause additional axial normal stress and lateral shear stress respectively ( $\mathrm{Ng}$ et al., 2014). This will increase the compressive stress in the pile.

Most previous studies are focusing on the investigation of thermal induced inner stress variation, but little on the influence of friction force of energy pile. Additionally, investigations of the thermo-mechanical behavior of PGHE with U-tube and W-tube has been partially studied, but there is a lack of thorough and comprehensive thermo-mechanical study on the PGHE with spiral coils. Therefore, the present work aims to investigate the interface behavior between pile and soil and the thermo-mechanical behavior of PGHE with spiral coils. An interface behavior test is introduced for analyzing the element behavior of concrete-soil under different thermal loads. A detailed experiment design concept and experiment progress are presented. Based on the experimental results, a numerical simulation model is established to systematically analyze the thermo-mechanical performance of PGHE with spiraltubes. Heating and cooling conditions are both simulated.

\section{INTERFACE BEHAVIOUR TEST}

The interface behavior between structural materials and soil is a critical parameter for the design and safety assessment of the pile foundation. Thus, the influence of thermal load on the interface behavior should be investigated first before any theoretical or numerical analysis for PGHE with spiral-tube.

\section{New interface test apparatus}

The traditional interface test is usually conducted by a direct shear apparatus, Figure 1 (a), which consists of two shear boxes. The specimens (structural materials and soil), contained in the box, is subjected to a constant normal load while a constant horizontal displacement is applied to the lower shear box. This displacement causes an increasing force at the interface, and a shear failure occurs when this force is beyond the shear strength. However, the traditional apparatus is failed to control the temperature and saturability during the shearing process, thus it cannot use to investigate the thermal effect.

Based on the traditional shear apparatus, a new direct shearing apparatus with temperature control (DSA-T) was designed, developed and employed. The new apparatus consists of an air pressure chamber, an air circulation pump, a heating/cooling system, a solution system and measuring/monitoring system, as shown in Figure 1 (b).

(a)

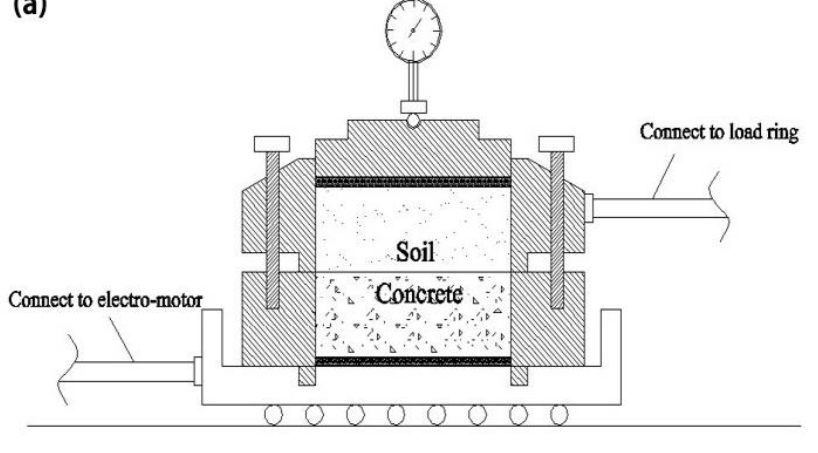

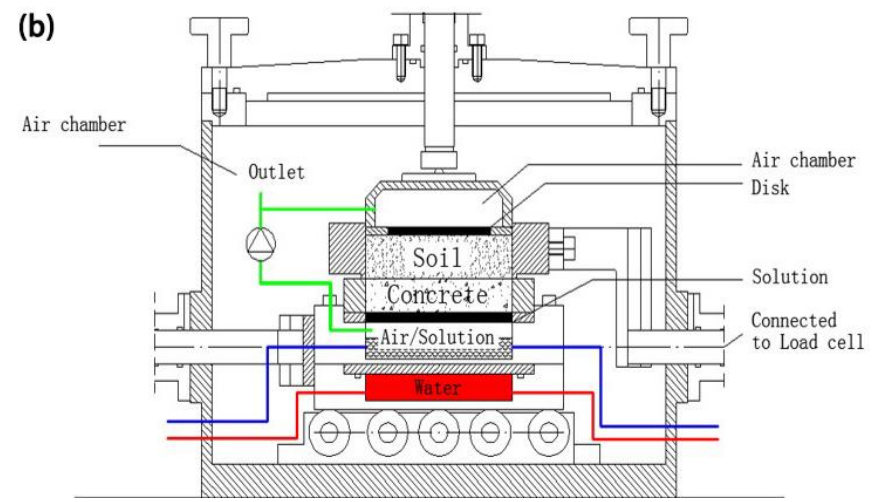

Figure 1 Schematic diagram of (a) a traditional direct shear apparatus and (b) the new direct shear apparatus with temperature control. 
One of the major differences of the new apparatus is the temperature control system that can simulate the heating and cooling process of energy pile. Another one is the suction control method. A solution circulation system is applied to control the humidity level in the air chamber so that the suction will be maintained during the shearing process. To enhance the heat and mass transfer in the air chamber, an air circulation pump is installed and has a maximum flow rate of $1 \mathrm{~L} / \mathrm{min}$. Thermal and humidity sensors are applied to monitor the heat and mass transfer in the shear box. The data logger reads all the measurements and communicates to the computer during the whole experiment.

\section{Experiment program}

Concrete is selected as the structure material in this soil-structure interface behavior experiment. For the soil material, two typical soil materials are selected. One is quartz sand, and the other one is clay. The experimental campaign can be divided into two groups: 1) interface test of sand-concrete and 2) interface test of clay-concrete. For the first part, interface test on sand-concrete, all the sand samples were sheared under dry conditions. All the prepared samples firstly experienced a consolidation process, and then a target thermal load was applied to the test chamber until the end of each shear test. After 24 hours, it is assumed that the test sample achieves the thermal equilibrium. Then, the sample was sheared under certain normal stress. Three normal stress, $50 \mathrm{kPa}, 100 \mathrm{kPa}$, and $150 \mathrm{kPa}$, are considered as the effective normal stress both for the interface test of sand and clay. For the interface test on clayconcrete, the loading path is basically the same with the sand-concrete test, but with a little difference in some aspects. All the clay soil samples are run under full saturated vapor pressure conditions. Both for these two interface behavior tests of sand-concrete and clay-concrete, three different temperature conditions, $8{ }^{\circ} \mathrm{C}, 24^{\circ} \mathrm{C}$ and $60^{\circ} \mathrm{C}$ are investigated.

Concrete. The concrete was prepared in the laboratory mixing cement, water, and aggregates, based on the JGJ $55-2011$. The target density of concrete is assumed to be around $2100 \mathrm{~kg} / \mathrm{m}^{3}$, thus the volume of aggregates is $250 \mathrm{~g}$ and the cement is $125 \mathrm{~g}$ mixed with $250 \mathrm{~g}$ water. The normal river sand is used as the aggregate with particles diameter equal or smaller than $1 \mathrm{~mm}$.

Quartz sand. The quartz sand, extracted from a China quarry, was selected for the interface experiment of the sand-concrete. The grain size of the test sand ranges between 0.008 and $1.0 \mathrm{~mm}$. The grain size distribution is presented in Figure 2 (a).

Sandy clay. The red clay soil, which is widely distributing in the east of China and used as a backfill material locally, was used in this study. The original soils used in this test were collected from a clay quarry at Hebei province, China. It can be seen in Figure 2 (b), that the clay has a fine fraction, as shown in the grain size distribution curve. This material is composed of $\mathrm{Fe}_{2} \mathrm{O}_{3}(15.2 \%), \mathrm{Al}_{2} \mathrm{O}_{3}$ (30.03\%), $\mathrm{SiO}_{2}(46.85 \%), \mathrm{K}_{2} \mathrm{O}(3.16 \%), \mathrm{MgO}(2.09 \%)$. The soil material was dried in an oven at $105^{\circ} \mathrm{C}$ over 24 hours and conserved tightly sealed. Before the shearing test, the specimens were mixed with distilled water to a target water content of $23 \%$ and filled into the shear box.

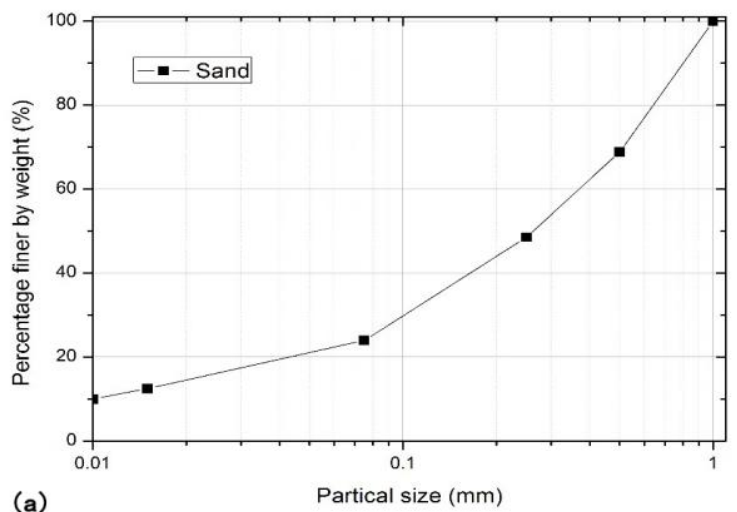

(a)

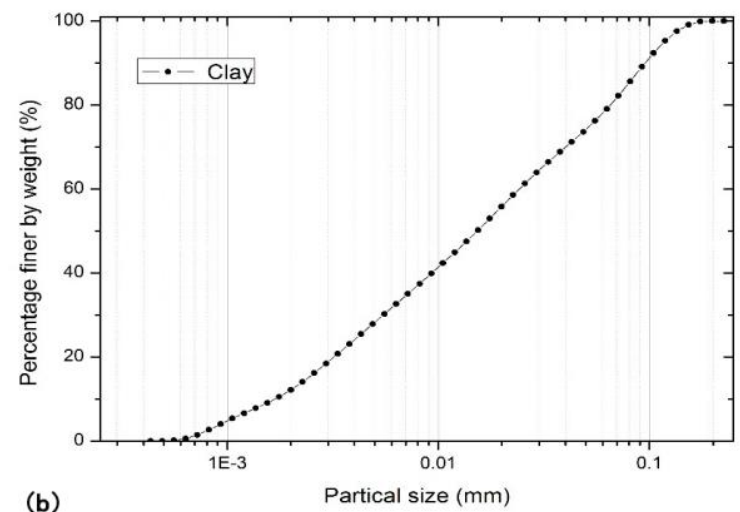

(b)
Partical size $(\mathrm{mm})$

Figure 2 Particle size distribution of (a) quartz sand (b) sandy clay. 


\section{NUMERICAL SIMULATION}

Based on the experimental results, a numerical simulation model is established to systematically analyze the thermo-mechanical performance of PGHE with spiral-tubes. The simulations were carried for a single energy pile with a diameter of $1.2 \mathrm{~m}$ and a depth of $15 \mathrm{~m}$. It is assumed that a spiral-tube was buried in the pile with a loop diameter of $1.0 \mathrm{~m}$ and a spiral pitch of $0.4 \mathrm{~m}$. The depth of the soil domain was set to be the double of the pile depth, and its radius was considered to be 15 times of the pile radius. The large enough soil domain is to ensure that the boundary condition of the soil has less influence for the heat transfer and mechanical performance of PGHE within the simulation period. Two typical heat transfer conditions (heating and cooling) was taken into consideration to simulate the working status of PGHE in winter and summer. As the influence of thermo-mechanical behavior of PGHE is not obvious in short time operation, it would be preferable to carry out a long-term simulation, i.e., 30 days, which would be a better way to understand the thermal and mechanical performances of PGHE.

The model and the mesh generation were built on the ABAQUS CAE. The sensitivity to the grid resolution of this numerical model has been considered and validated. In this analysis, the spiral tube is simplified as a series of separated ring-coils, and the whole calculation domain is axial symmetry. Thus, this three-dimensional problem can be simplified as an axial symmetry model. Three kinds of physical mechanisms were taken into consideration: 1) the heat transfer process from the geothermal heat exchanger to concrete pile and soil, 2) the mechanical behavior between pile and soil, and 3) the additional thermal stress induced by heat transfer.

\section{Boundary conditions and material properties}

As the radius of soil domain is more than ten times than that of the pile, the far-field boundary of soil was treated as adiabatic surfaces and blocked the displacement in the radial direction. The bottom boundary of soil domain was given a constant temperature of $20^{\circ} \mathrm{C}$, which was equal to the initial temperature of the whole calculation domain. The boundary condition at the top surface of soil and pile was also assumed to be a constant temperature of $20^{\circ} \mathrm{C}$. A fixed mechanical boundary condition was applied at the soil bottom to ensure that the vertical and horizontal displacements at this position are zero. As the main focus is the thermo-mechanical performance of pile and soil, the fluid dynamic within the spiral heat exchanger was not be simulated in this study, which was simplified as a heat flux boundary condition applied on the pipe surface. The heat injection rate is assumed to be $120 \mathrm{~W} / \mathrm{m}$ to simulate the heating process of GHE, and the heat extraction rate is considered to be $40 \mathrm{~W} / \mathrm{m}$.

Both the pile and soil were assumed to be a purely elastic material, and the plastic deformation of soil is not considered. The metrical properties of soil are based on the results of the interface behavior tests, proposed in the last chapter, and the main properties for this numerical study are summarized in Table 1. Under each heat transfer condition (heating or cooling), two mechanical load behaviors were conducted: one is that no load force was applied on the pile top and the stress was only induced by gravity and temperature variation; the other one is that the pile is under an axis displacement, and both the mechanical and thermal loads were applied on the pile. The displacement rate of pile top was assumed to be $5 \mathrm{~mm} /$ day. 
Table 1 Summary of concrete and soil properties for the simulation cases

\begin{tabular}{|c|c|c|c|c|}
\hline \multicolumn{3}{|c|}{ Material } & \multirow{2}{*}{ Concrete } & \multirow{2}{*}{ Soil } \\
\hline Item & Symbol & Unit & & \\
\hline Conductivity & $\mathrm{k}$ & $\mathrm{W} /(\mathrm{m} * \mathrm{~K})$ & 1.628 & 1.82 \\
\hline Density & $\rho$ & $\mathrm{kg} / \mathrm{m} 3$ & 2500 & 2500 \\
\hline Specific Heat & $C_{\mathrm{p}}$ & $\mathrm{J} /\left(\mathrm{kg}^{*} \mathrm{~K}\right)$ & 837 & 880 \\
\hline Young Modulus & $\mathrm{E}$ & $\mathrm{Pa}$ & $2.8 \mathrm{E}+10$ & $5.2 \mathrm{E} 6$ \\
\hline Poisson's Ratio & $\mu$ & 1 & 0.25 & 0.35 \\
\hline Coefficient of Thermal Expansion & $\alpha$ & $1 / \mathrm{K}$ & $1.2 \mathrm{E}-5$ & $1.75 \mathrm{E}-5$ \\
\hline Internal Friction Angle & $\delta$ & 0 & - & $15.51 / 17.66 / 22.05$ \\
\hline Cohesion & c & $\mathrm{kPa}$ & - & $4.57 / 4.61 / 7.51$ \\
\hline
\end{tabular}

\section{RESELUTS AND DISCUSSION}

\section{Interface behavior test}

The test results of the sand-concrete and the clay-concrete interface are summarized in Figure 3.
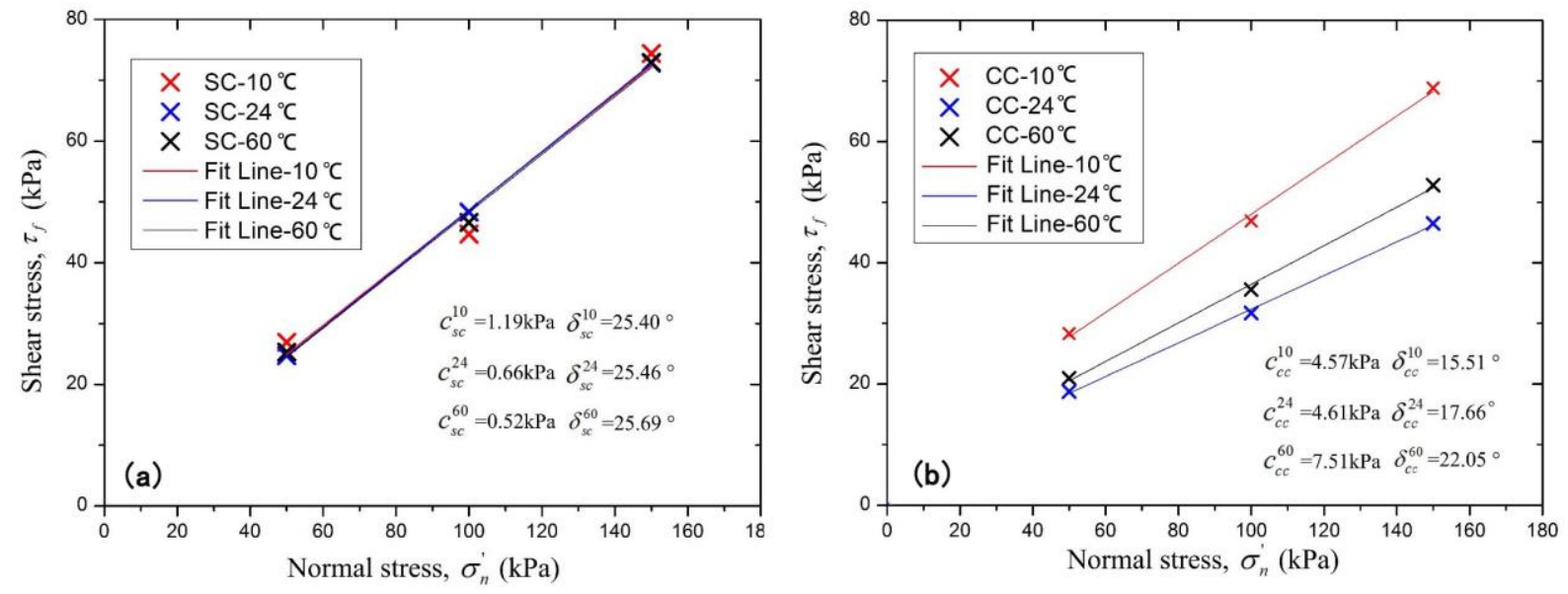

Figure 3 Relationships between shear strength and net normal stress under different thermal load during (a) sandconcrete and (b) clay-concrete interface test.

As shown in Figure 3 (a), the interface response of sand-concrete either at high or low temperature conditions does not have the obvious difference to that at normal temperature condition. The friction angle $(\delta)$ of sand-concrete is found to be 25.51 degree on average. But for the case of clay-concrete, Figure 3 (b), the interface friction properties (friction angle and adhesion strength) are enhanced by the high temperature. Compared with the case of normal temperature, the adhesion strength has an improvement of about $63 \%$, and the friction angle increased by $24 \%$ at high temperature. The water content loss in high temperature condition should be the main causes of the increases of the adhesion strength and the friction angle. According to the experiment data, the water content of $60{ }^{\circ} \mathrm{C}$ is $18.5 \%$, and in the case of $24{ }^{\circ} \mathrm{C}$ is $28.3 \%$. Conversely, the friction properties decrease with the as the temperature dropped. In the simulation model, the different relationship lines of failure criteria were applied on the different thermal conditions, and in each thermal condition the failure criteria is appropriate for all stress levels. 


\section{Thermo-mechanical response with no axis load}

If there is no additional mechanical force applied on the pile top, the stress within the pile foundation should only come from the gravity. Therefore, the initial stress increases linearly with the pile depth, and the frictional shear force should be closed to zero, as shown in Figure 4.

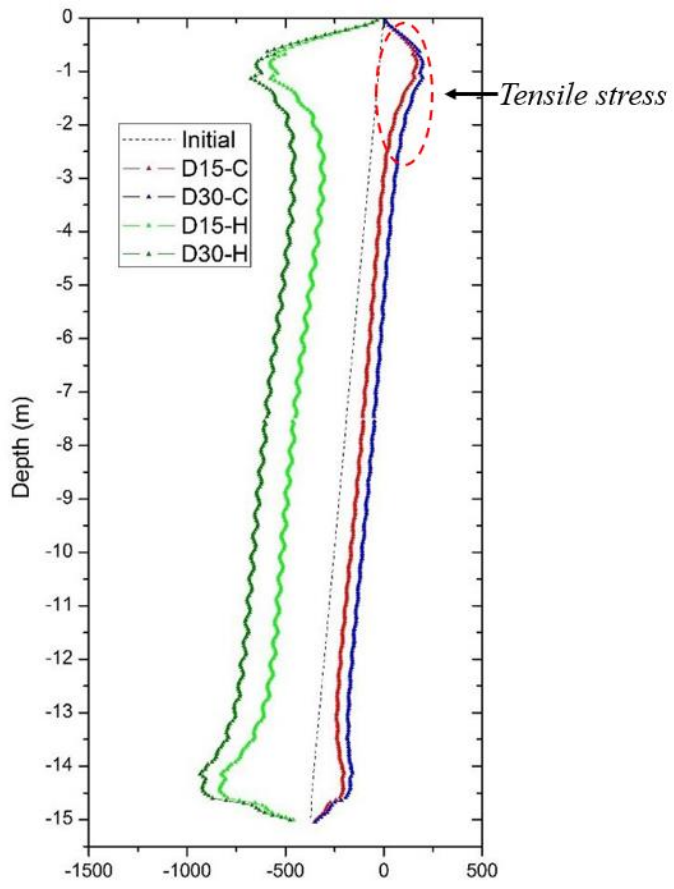

(a) Stress $(\mathrm{kPa})$

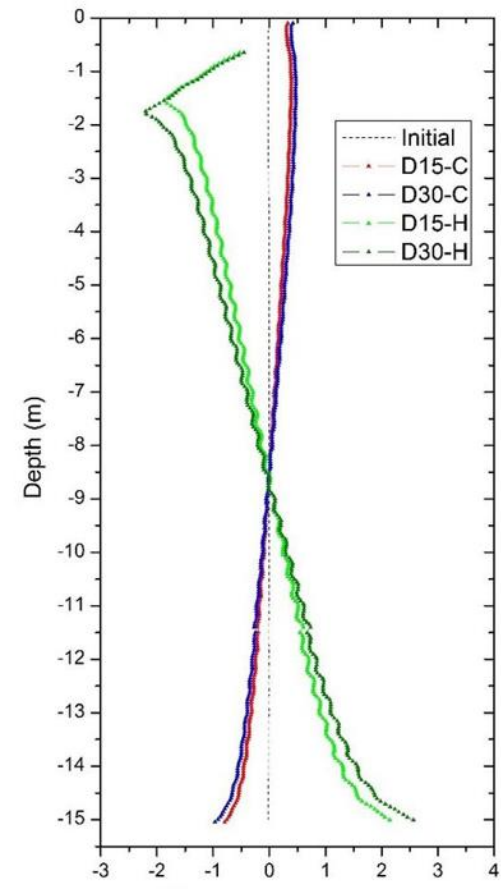

(b) Shear stress $(\mathrm{kPa})$

Figure 4 Distribution of (a) vertical stress along the pile axis and (b) shear stress along the pile side at cooling and heating conditions with no axial force

When the spiral heat exchanger injects heat energy into the concrete pile, the thermal stress was excited and pushed the pile to expand from the null point to the top and bottom. In this case, the null point was located at the depth of $8.5 \mathrm{~m}$. A positive shear stress (assuming the direction from the pile bottom to the top is positive) is mobilized under this null point, and a negative one occurs above this point. An inflection point can be observed near the top of the pile, which should be the consequence of the decrease of the normal contact force. An additional thermal stress was mobilized simultaneously. As shown in the stress distribution curves, this thermal load induced stress along the axis is obvious but less than $5 \%$ of the concrete ultimate compressive strength. The maximum compressive stress is equal to $5.75 \mathrm{Mpa}$, which was detected in the area near the spiral heat exchanger pipe.

For the case under the cooling condition, a similar phenomenon was shown, but the friction direction is opposite to the case of the heating condition. The temperature change induced a contraction behavior of the pile, and the friction was mobilized to restrict this behavior. The stress distribution curves along the pile axis show that the pile suffered an additional pressure stress with the temperature increase and tensile stress with the temperature decrease. But, it should be pointed out that the tensile stress only occurs near the pile top, and the tensile stress fades away with an increase in depth. The maximum tensile stress detected near the spiral heat exchanger is $0.4 \mathrm{Mpa}$, which has almost reached $50 \%$ of the ultimate tensile strength of normal concrete pile. 


\section{Thermo-mechanical response under axial force}

Figure 5 shows that the shear stress along the pile side and the stress distribution along the pile axis under different thermal loads. Clearly, the temperature rise can induce a stress increase in the pile foundation. It could be noted that the stress curve of heating increase greatly near the pile top. This is due to the ununiformed distribution of the load force. The load force at the center of pile surface is always lower than that of the around area. The maximum compressive stress is found to be $6.25 \mathrm{MPa}$ at the depth of $1.12 \mathrm{~m}$, and at the same position, the pressure stress in the case of no thermal disturbance is only 4.96MPa. A $0.5 \mathrm{MPa}$ decrease was shown in the case of the cooling condition.

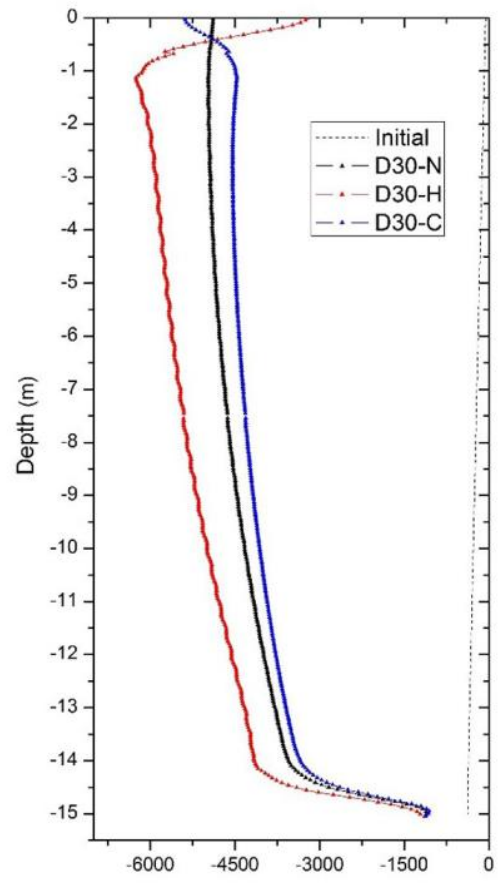

(a) Axial Stress (kPa)

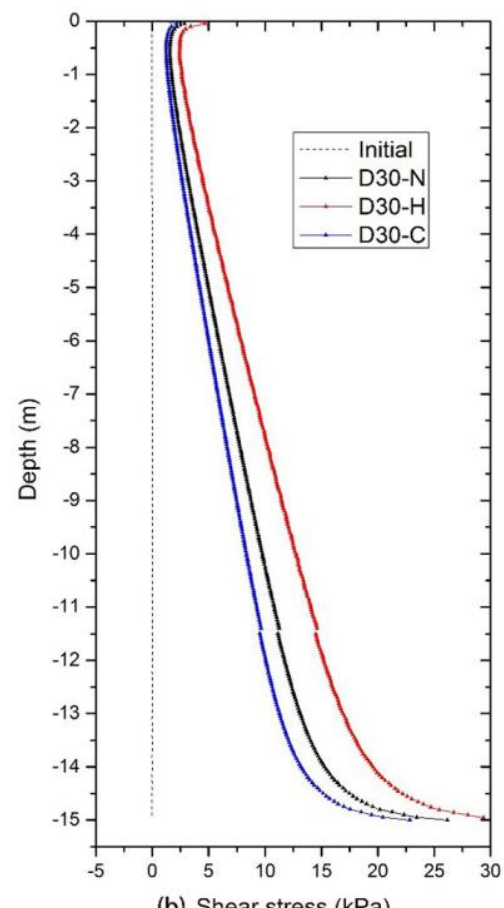

(b) Shear stress $(\mathrm{kPa})$

Figure 5 Distribution of (a) vertical stress along the pile axis and (b) shear stress along the pile side at cooling and heating conditions under axial force.

The shear stress along the pile is almost with linear distribution. It is because the compressive deformation of the pile is relatively small, and the slip between pile and soil is uniform. As seen in Figure $\mathbf{5}$ (b), the shear stress can be enhanced by the temperature rise, and weakened by the heat absorbing process. It should be noted that all the stress force is compressive stress, and no tensile stress is mobilized in the pile when the pile is loaded with head force. The temperature does not only increase the friction angle for the interface between soil and pile, but the expansion deformation is also increased by the normal pressure on the interface. These two behaviors are combined to generate an enhanced ratio of $48 \%$ on the first third of the pile, when the PGHE operation in the heating mode. This enhancement effect is more remarkable at the top of the pile, and decreases with the pile depth. A similar phenomenon can also be observed in the case of cooling simulation. The average enhancing ratio at 30' days of heating operation is equal to $34.40 \%$. On the contrary, the temperature decrease caused a weakening effect on the shear stress, with an average weaken ratio of $15.37 \%$. 


\section{CONCLUSION}

The application of pile GHE faces an innovative challenge for geotechnical design. The temperature within the concrete pile and soil always changes during the heating or cooling season. This temperature change can induce additional thermal deformation and stress in the pile and physical property changes of soil.

The interface test shows that the friction parameters (friction angle and adhesion strength) of the clay-concrete interface are enhanced by the high temperature. Compared with the case of normal temperature, the adhesion strength has an improvement of about $63 \%$, and the friction angle increased by $24 \%$. Conversely, the friction properties decrease slightly with the temperature reduction. Based on these tested results, a simulation model was established to investigate the themo-mechanical performance of PGHE with spiral-tubes in full size. As the simulation results demonstrated, the heat exchange process of GHE has a great effect on the skin friction behavior of the pile. A $34.4 \%$ increase of bearing capacity is observed in the case of heating simulation and a $15.37 \%$ capacity decrease has been found in the case of cooling simulation.

\section{ACKNOWLEDGMENTS}

This work is supported by the Hong Kong RGC General Research Fund (PolyU 5176/13E).

\section{NOMENCLATURE}

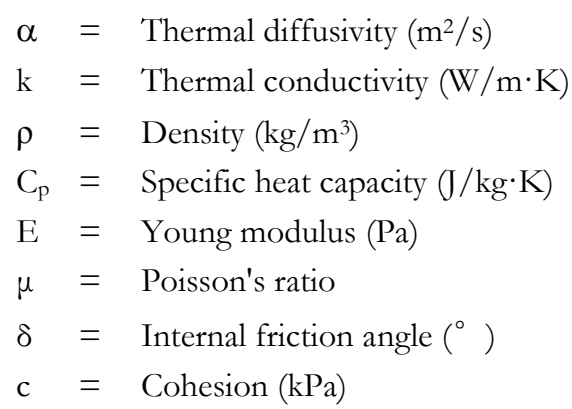

\section{REFERENCES}

Cui, P., Diao, N., Gao, C., \& Fang, Z. (2015). Thermal investigation of in-series vertical ground heat exchangers for industrial waste heat storage. Geothermics, 57, 205-212.

Di Donna, A., Rotta Loria, A. F., \& Laloui, L. (2016). Numerical study of the response of a group of energy piles under different combinations of thermo-mechanical loads. Computers and Geotechnics, 72, 126-142.

Knellwolf, C., Peron, H., \& Laloui, L. (2011). Geotechnical analysis of heat exchanger piles. Journal of Geotechnical and Geoenvironmental Engineering, 137(10), 890-902.

Laloui, L., Nuth, M., \& Vulliet, L. (2006). Experimental and numerical investigations of the behaviour of a beat exchanger pile. International Journal for Numerical and Analytical Methods in Geomechanics, 30(8), 763-781.

Ng, C., Shi, C., Gunawan, A., \& Laloui, L. (2014). Centrifuge modelling of energy piles subjected to heating and cooling cycles in clay. Géotechnique Letters, 4(October-December), 310-316.

Wang, D. Q., Lu, L., \& Cui, P. (2016). A novel composite-medium solution for pile geothermal heat exchangers with spiral coils. International Journal of Heat and Mass Transfer, 93, 760-769. 